\title{
Geodemographic analysis of tuberculosis patients in Karachi, Pakistan
}

\author{
Muhammad Miandad, Farkhunda Burke ${ }^{a}$, \\ Syed Nawaz-ul-Huda ${ }^{\mathrm{b} *}$, Muhammad Azam ${ }^{\mathrm{c}}$
}

\author{
a University of Karachi, Pakistan \\ b Dawn Media Group, Pakistan \\ c Federal Urdu University of Arts, Sciences and Technology Karachi, Pakistan
}

Tuberculosis (TB) is endemic in Karachi, Pakistan, and even with the discovery of other infectious diseases no significant change is evident in its epidemiological profile while analyzing the temporal incidence. There is significant evidence to support the fact that poverty is the leading cause of TB. A number of scholarly analyses have documented associations among patients' characteristics (sex, age group); social factors (education, origin of the patient, smoking, alcohol and drug use); environmental factors (house types, room density, source of water, garbage collection and disposal), and economic factors etc. The purpose of the present study is to provide cogent and relevant arguments for the characteristics of tuberculosis patients in terms of social and economic profiles in the study area. Forty-nine selected variables have been used in the present study for analysis. Three factors have emerged as responsible for the spread of tuberculosis in the study area. An insight into variables for Factor I reveals that features related to urbanization appear to be categorically responsible for the spread of TB in Karachi, especially among the white collar persons and low, middle-class residents. The results of the present study can help the city authorities for improving downtown areas renovation as per quality of life demand.

Key Words: factor analysis, tuberculosis, Karachi, epidemiology, ecological impacts.

Article Info: Received: October 30, 2014; Revised: October 24, 2015; Accepted: November 18, 2015; Online: November 30, 2015.

\section{Introduction}

Mycobacterium tuberculosis (MTB) is composed of closely related bacterial sub-

\section{* Corresponding author}

Address: DAWN-GIS, Geospatial and Statistical Research Division, Dawn Media Group, Pakistan, Dr. Ziauddin Ahmed Road, Civil Lines, Karachi, Pakistan.

Phone: +92333-3177399 | Email: nawaz_huda@hotmail.com 
species which affect both human beings as well as animals (Wirth et al., 2008). Tuberculosis being highly contagious, its infection has been responsible for the high human casualty to the tune of around a million persons in the world in 2013, according to the World Health Organization (WHO, 2013). Tuberculosis (TB) is endemic in Karachi, Pakistan, and even with the discovery of other infectious diseases no significant change is evident in its epidemiological profile while analyzing the temporal incidence. The increasing number of diagnostic centers for $\mathrm{TB}$ patients indicates that a limited number of centers face the burden of TB patients.

Data for Karachi reveals that there were large number of patients, especially in the towns of New Karachi and Liaquatabad, where the rate of incidence due to TB in 2010 was 8.5 cases per 100000 inhabitants, while in all of Karachi the hospitalization rate for the year was 7.2 cases per 100000 population (Miandad et al., 2014).

In view of the gravity of the problem with reference to $\mathrm{TB}$, several studies relating to this serious health issue have been published which were based on primary and secondary data collected from patients registered at diagnostic centers (Kruuner et al., 2001; Qazi et al., 2009; Jenkins et al., 2014) and was aimed at the description of epidemiology of different types of TB, its insurgency and drug resistance (Nunes, 2007;Middelkoop et al., 2009; Yazdani et al., 2010;Wang, et al., 2012; Roza et al., 2012; Borraccino et al., 2014).

There is evidence that low profile of human life is the primary cause of infectious diseases and a number of scholarly studies have documented association between characteristics of patients (sex, age group), their social factors (education, income, source of revenue, origin of patient, addiction to alcohol, smoking, drug use, etc.), and environmental factors (housing, room density, employment conditions, source of water at home, garbage collection and disposal etc. (Souza et al., 2000; Ezzati and Lopez, 2004; Lonnroth, et al., 2009).

Among the social, environmental and biological determinants of $\mathrm{TB}$, most encompass the poorer classes of the population. Risk factors recognize poverty as a root cause (Oxlade and Murray, 2012; Harlingand Castro, 2014), and there is an emergent need not only to intervene on financial status but also on the proximal risk factors to which the poor are significantly being exposed. Although, some epidemiological studies have pursued to measure the impacts of these factors, only a few have made efforts to identify explicitly the routes and methods by which poverty culminates in TB (Hossain et al., 2012; Mangtani et al., 1995). Although geographical literature regarding the association of environmental and social factors pertaining to association with TB exists for various countries of the world, few studies have been made in Pakistan (NTPP, 2012; Shafqat and Jamil, 2012; Siddiqui et al., 2011).

Since the mid-1980s, tuberculosis notifications have increased in both developing and developed countries (Hayward et al., 1995). The purpose of this study is to prove that the rise in tuberculosis may be related to an increase in underlying social deprivation, geo-demographic status and ecological factors among the population of the study area. PCA based Factor Analysis has been employed for the 49 variables deemed relevant to cover various aspects of the present investigation. Factor Analysis has been employed to explain correlations among the original variables thereby facilitating the development of cause and effect model regarding the quality of life of the patients. 


\section{Materials and methods}

Study Area

Karachi, the thickly populated port city of Pakistan, comprises 16 million (estimated) souls over $800 \mathrm{~km}^{2}$ area while 0.9 million (estimated) are living on a covered area of $2800 \mathrm{~km}^{2}$. Located strategically between 24.750 to $25.656 \mathrm{~N}$ and 66.653 to $67.574 \mathrm{E}$ on the coast of the Arabian Sea, northwest of the Indus delta, it covers an area of $3600 \mathrm{~km}^{2}$ (Huda et al., 2013a). The city falls in an administrative Division of Sindh Province, comprised of six districts. Due to the perspective of micro level incidence, the unit of study selected is the previously Local Government setup which was composed of 18 towns and 6 military administered cantonments.

\section{Research design and sample size}

The present study followed standard techniques for collection of data and analysis. The questionnaire was designed under the domain of Pakistan TB Control guidelines and characteristics of the city's socioeconomic conditions (Table 1). The questionnaire consisted of queries pertaining to basic information regarding patients, their socioeconomic and ethnic backgrounds. Questions related to ecological and biological conditions, awareness regarding symptoms of the disease and other related information were also part of the questionnaire in order to achieve a comprehensive coverage of the objectives of the study and collection of registered TB patients (secondary data) from National Tuberculosis Control Program, Karachi Sindh, Marie Adelaide Leprosy Centre, SATA (Sindh Anti-TB Association), PCS (Pakistan Chest Society), Green Star, TB centers, hospitals and publications of the WHO, World Bank and Stop TB Partnership.

A Likert scale format was designed and used to elicit individual each patient's responses. Subsequent to significant discussions with experts 07 major questions were selected. The score range on each question depends on categories answers, so the total for the seven questions outcomes were 49. Data was collected through face to face interviewing of patients at TB diagnostic centers in the study area. The average prevalence of patients (p) at a confidence level 95\%, confidence interval (CI) of $4($ alpha $=0.05)$ and a deviation $(d)$ of 0.02 was $20 \%$. The acceptable sample size was thus determined to be 1260 as per last population census. The questionnaire survey, which was conducted over a period of eight months (March to October 2013). Data were entered into a Microsoft Excel spreadsheet and analyzed with SPSS Version 20.

\section{Characteristics of variables}

The present work has been conducted through a compilation of indicators which provide a comprehensive direction to researchers for calculating the complicated indices and conducting quality research (Table 1). Such a procedure has been utilized on the statement that doing so must be beneficial and a perfect substitute for examining several individual procedures, species and so on (Landres, 1992). 
Table 1. Selected Variables

\begin{tabular}{|c|c|c|}
\hline No. & Abbreviation & Variables \\
\hline 1 & Unmarried-TR & Unmarried / Total Respondents \\
\hline 2 & EPTB-TR & Extra pulmonary TB/Total Respondents \\
\hline 3 & Above-SSC-TER & Matric and above education/Total Educated Respondents \\
\hline 4 & 08-11-PPR-TR & Person per room/Total Respondents \\
\hline 5 & Female-TR & Female respondent/Total Respondents \\
\hline 6 & Below_SSC-TER & $\begin{array}{l}\text { Below Secondary School Certificate/Total Educated } \\
\text { Respondents }\end{array}$ \\
\hline 7 & 04-07-PPR-TR & Person per room 04-07/Total Respondents \\
\hline 8 & FH_Continue-TFH & Patients family history whose treatment continue \\
\hline 9 & Unemp-TMR & Unemployment/Total Male Respondent \\
\hline 10 & $A>15000-T R$ & Income more than 15 000/Total Respondents \\
\hline 11 & FH_Cured-TFHR & Patients cured in families/Total Respondents \\
\hline 12 & Family_HistoryTB & Patients having TB patient any time \\
\hline 13 & Punjabi-TR & Punjabi speaking/Total Respondents \\
\hline 14 & Meat-01-/week-TR & Patients eat meat once in a week/Total Respondents \\
\hline 15 & Sep-Res-TR & Patients who live separate room/Total Respondents \\
\hline 16 & Un-Plan-TR & Living in unplanned area/Total Respondents \\
\hline 17 & Garbage-TR & Garbage near house/Total Respondents \\
\hline 18 & Urdu-TR & Urdu speaking/Total Respondents \\
\hline 19 & Aware-No-TR & Do not have awareness regarding TB/Total Respondents \\
\hline 20 & Pat-Resi-combined-TR & Patients who sharing accommodation/Total Respondents \\
\hline 21 & Precau-Y-TR & $\begin{array}{l}\text { Awareness regarding precautionary measures/Total } \\
\text { Respondents }\end{array}$ \\
\hline 22 & Local Treat-TR & Patients who got treatment from local area/Total Respondents \\
\hline 23 & Non-ownership-TR & Living in non-ownership houses/Total Respondents \\
\hline 24 & Seraiki-TR & Seraiki speaking/Total Respondents \\
\hline 26 & B $<15000-T R$ & Income less than $15000 /$ Total Respondents \\
\hline 27 & PTB-TR & Patient with pulmonary TB/Total Respondents \\
\hline 27 & Male-TR & Male respondent/Total Respondents \\
\hline 28 & other-L-TR & Other languages/Total Respondents \\
\hline 29 & Plan-TR & Patients who belong to planned area/Total Respondents \\
\hline 31 & Katcha-TR & Katcha house residents patient/Total Respondents \\
\hline 32 & Resurgence-TR & Resurgence/Total Respondents \\
\hline 33 & H_Wife-TFR & Housewives patients/Total Female Respondents \\
\hline 34 & FH-Died-TFHR & Any family member died due to TB/Total Respondents \\
\hline 35 & 01-03-PPR-TR & Person per room 01-03/Total Respondents \\
\hline 36 & Pashto-TR & Pashto/Total Respondents \\
\hline 38 & Profes-TMR & Professional employee/Total Male Respondents \\
\hline 39 & Illit-TR & Illiterate/Total Respondents \\
\hline 40 & Private-TMR & Private job/Total Respondents \\
\hline 41 & Labr-TMR & Laborer/Total Respondents \\
\hline 42 & More-06-m & More than 06 months diagnosis/Total Respondents \\
\hline 43 & Cig.-smoker-TMR & Regular smoker/Total Male Respondents \\
\hline 44 & BCG-N-TR & Patients who have not vaccinated of BCG/Total Respondents \\
\hline 45 & Diag-06-month-TR & Before 06 month diagnosis/Total Respondents \\
\hline 46 & Diag-03-month-TR & Diagnosis within 03 months/Total Respondents \\
\hline 47 & Married-TR & Married/Total Respondents \\
\hline 48 & Govt. S-TMR & Gov. Servant patients/Total Respondents \\
\hline 49 & Food-02/d & Take food twice daily (including breakfast)/Total Respondents \\
\hline
\end{tabular}


TB patients not only transmit mycobacterium thus entailing serious effects on physical health, social and economic wellbeing (Aggarwal, 2010) but the social repercussions may include loss of job, disturbance on marital life, ostracism by family members and the local community, even loss of shelter (Lawn, 2000). An amplified series of danger ranging from TB sickness to active disease relate with starvation, due to the pessimistic impact of micro and macro nutrient shortages on the cell-mediated resistant system (Cegielski et al. 2004: McMurray and Cegielski, 2007). Malnutrition weakens the immune system and increases the chances of host's receptiveness to infection. This infection leads to a reduction in appetite, micronutrient as well as nutrient malabsorption and distorted metabolism leading to wasting, hence can become a source contributor to conditions liable to promoting the risk of TB.

A close relationship has also been estimated between poverty and TB (Nair et al., 1997; Diamond et al., 2001; Kaulagekar et al., 2006; Diwan, 1999). Education is the vital force of human civilization provides choices to people regarding the varieties of lives they wish to live, but also enables them to express their views amidst the community in which they live but also imbibes confidence in their personal relationships (UN, 2005). Educational achievements are stepping-stones for ensuring and availing better-earning opportunities which nurture the roots of the quality of life of human beings. It not only bestows socioeconomic status and stability to its owners but makes available to individuals a wide range of alternatives for the manner in which they may arrange their lives. It inculcates awareness regarding all facets of life inclusive of health and diseases (Khan et al., 2006). In the study area, the uneducated populace is not only partly responsible for creating social and economic problems but are also a great cause of backwardness, a phenomenon visible in densely populated settlements (Burke et al., 2008).

It has also been suggested that improvement of the economy, better housing and living conditions, attainment of education for both males and females, and reduction of poverty are long term goals for reduction of susceptibility to diseases, especially TB. According to Gupta (2009), smoking was one of the leading causes of TB. Poor people are compelled to reside in damp, dark, dusty, ill-ventilated houses with no heating which promote the survival of TB bacteria. Due to a shortage of money, people suffer from stress, causes of the weakening of the immune system, henceforth contraction of TB. People in developing countries with a shortage of money were unable to purchase medicines for the treatment of TB.

Living in overcrowded housing areas coupled with housing congestion magnify contact with coughing and sneezing people harboring TB germs in their lungs and throats which can be a dominant cause of the spread of TB. The density of people also enhances the spread of TB, and highly positive correlation has been observed between them (Ploubidis et al., 2012). Literacy plays a significant role in improving the quality of health as well as life. Secretary General UNO, Ban Ki-moon stated on 8th September 2008, that it has a direct impact on health as it not only prevents reading of medical instructions and such people are oblivious of facts related to infectious diseases like TB and other diseases like AIDS, malaria, etc. TB being contagious, it spreads more rapidly among the poor people of developing countries, the majority of who live in houses built of mud/stone/wood/bricks, etc. Mayer (2006), found in his research that lack of mobility or permanence of settlement has a tendency of favoring stability in the spatial distribution of 
infection. It has been reviewed that $97 \%$ of total TB cases is detected in low-income countries. Poverty forces people to live in congested, ill-ventilated dwellings, as a result of which infectious diseases thrive.

\section{Data collection and statistical analysis}

Data was collected through questionnaire during eight months period among patients in the 18 towns of Karachi diagnosis centers enlisted on the National Tuberculosis Program medical records. Spatial analysis of temporal data within the precincts of town boundaries have been portrayed through GIS application, while for multivariate analysis variables were grouped into the following dimensions: patient characteristics (sex, age group, race); social factors (education, income, source of revenue, origin of the patient, addiction to alcohol, smoking and drug use); and environmental factors (housing types, room density, employment conditions, masonry housing, source of potable water for household use and consumption, garbage around settlements).

With the help of Principal Component Analysis (PCA), three factors have been documented for explaining the spread of tuberculosis in the study area. Data was analyzed using SPSS 20 for Windows. Factor Analysis, one of the easiest, reliable and comprehensive techniques for the multivariate study has been utilized (Weinbach and Grinnell, 2001) by Charles Spearman (Cattell 2008) as a means of analyzing the results from intelligence tests and later used by other disciplines. The technique clearly investigates the variables that may be responsible for the phenomena under observation. It has the advantage of reducing the enormous array of data into compact factors (Abdi et al., 2013).

\section{Results and discussion}

Figure 1 reveals the spatial pattern of TB incidence in the towns of Karachi from 2010 to 2013. An insight into the spatial scenario of 2010 reveals that the highest incidence was found in Liaquatabad, Malir and New Karachi towns ranging from 1 001-1 500 cases. Korangi, Gulshan-e-Iqbal, Saddar, and Lyari had cases between 501-1 000 while the other 11 towns had below 500 cases. In 2011, highest incidence was found in Korangi town (2 501-3 000) followed by Liaquatabad (2 001-2 500) and Saddar towns (1 501-2 000). New Karachi and Malir towns had incidence range between 1 001-1 500, Gulshan-e-Iqbal, Orangi and Lyari towns between 501-1 000 and the remaining 10 towns below 500 cases. In 2012, the highest number of cases were found in Korangi Town (2 001-2 500).Liaquatabad had the second highest range i.e. between 1501 and 2 000; Saddar, Malir and New Karachi had the third highest range, i.e., between $1001-1$ 500. Gulshan-e-Iqbal, Orangi and Lyari towns had between 501-1 000 cases while 10 towns had below 500 cases.

In 2013, highest cases were found in Korangi and Saddar towns ranging between 2001-2 500. Liaquatabad town had an incidence between 1 501-2 000, New Karachi and Malir towns' incidence ranged between 1 001-1 500; Gulshan-eIqbal, Orangi and Lyari towns had between 501-1 000; and 10 towns had cases below 500 . 


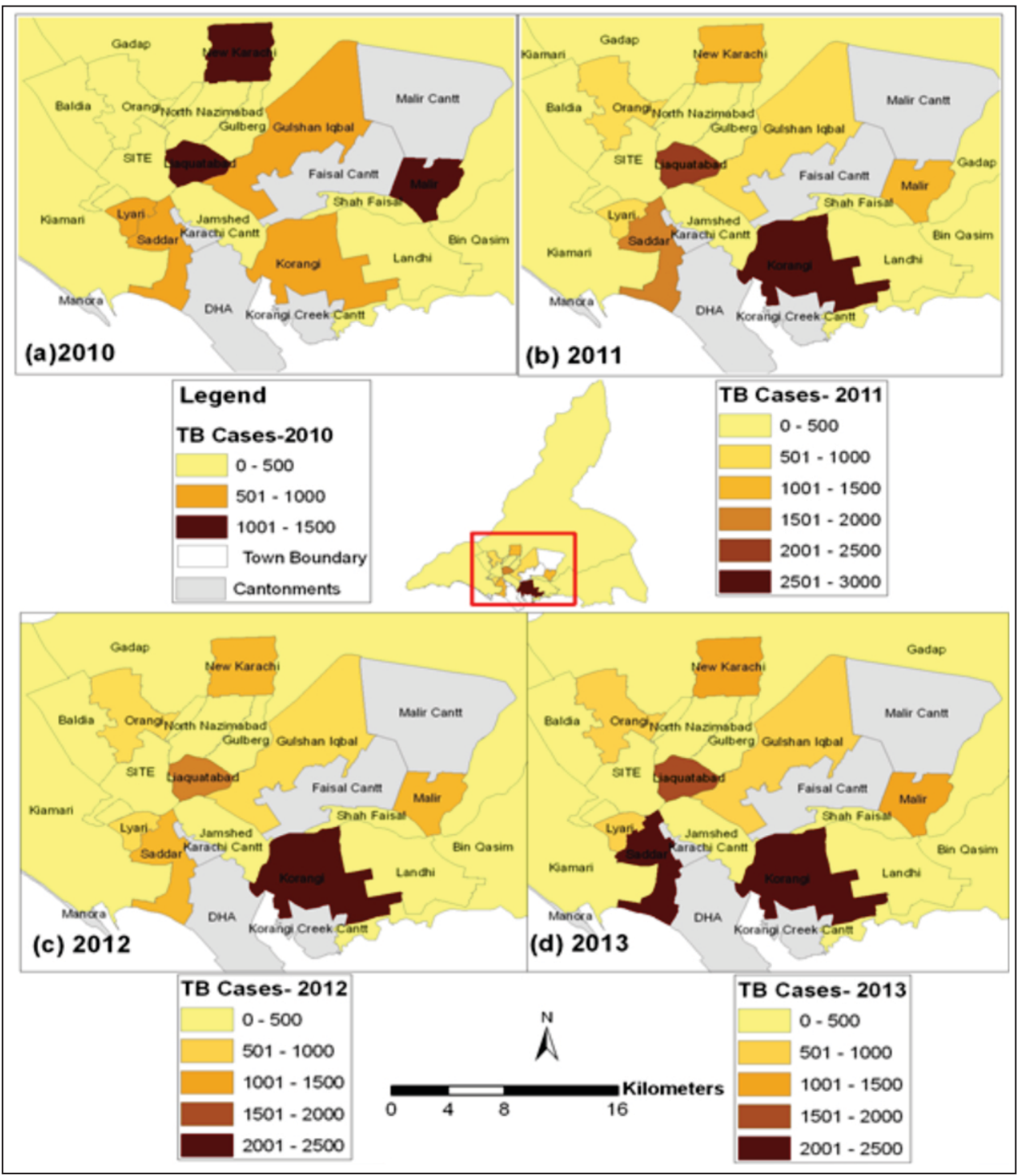

Figure 1. Spatial Patterns of TB Incidence in Towns of Karachi- 2010-2013

The spatiotemporal analysis revealed an interesting scenario observed in 06 towns (i.e. Gulshan-e-Iqbal, Korangi, Liaquatabad, Lyari, Malir and New Karachi), that these towns had $63.47 \%$ cases out of the total registered cases, which were thus the most highly vulnerable. The remaining 12 towns had $36.53 \%$ of the TB cases. The population of towns with high incidence comprised $36 \%$ of the city's population while $64 \%$ of the population were residents of the other 12 towns. These 06 towns had 63.35, 60.94 and $63.11 \%$ of the cases in 2011, 2012 and 2013 respectively. NTP should pay more attention towards these towns for the eradication of the disease.

For the investigation of cause and effects relationship in the perspective of quality of life of tuberculosis patients with reference to the increase of TB in the study area, PCA-based factor analysis was employed for the 49 variables deemed 
Table 2. Rotated Sums of Squared Loadings

\begin{tabular}{|c|c|c|}
\hline Total & \% of Variance & Cumulative \% \\
\hline 26.436 & 53.95 & 53.95 \\
\hline 15.852 & 32.35 & 86.30 \\
\hline 3.274 & 6.68 & 92.98 \\
\hline
\end{tabular}

relevant to cover various relevant aspects. Table 2 explains total variance extracted by PCA technique. Table 3 shows three factors and their variance that have been extracted from the selected variables. The data pertaining to the 49 variables explains $92.98 \%$ of the total variance. The first Factor explains $53.95 \%$ of the variance, with more than $50 \%$ of the variables showing the strong correlation among themselves, while Factors II and III explain 32.35 and $6.68 \%$ respectively of the variance. The results prove that the rise in tuberculosis may be related to an increase, in underlying social deprivation, geodemographic status and ecological factors among the population of the study area.

\section{Factor I-Socioeconomic and demographic Status}

The first factor accounts for $53.95 \%$ of the total variance with reference to all the selected variables (Table 2). The nature of the factor is clearly identifiable by very high positive loadings more than 0.50 for 38 variables and one high negative loading. An insight into the variables for Factor I (Table 3) reveals that features related to unbalanced urbanization appear to be categorically responsible for the spread of TB in Karachi, especially among poor status residents. Unstable social life, especially due to low, restricted incomes has emerged as significant among the TB patients. All variables recording positive (1.0 to 0.50$)$ and negative ( -1.0 to -.50$)$ loadings reveal that they behave in a certain consistent fashion. Positive loadings have been recorded for all attributes that are responsible for the occurrence and spread of TB, while the negative loadings for food consumed twice a day, shows just the reverse (Huda et al., 2013b). It explains the significant role of diet in curtailing as well as fighting the disease.

Highest positive loadings of variables have emerged for unmarried to total respondents (0.98), extrapulmonary patients (0.96), secondary school certificate and above educated (0.96), 08-11 persons per room residents (0.95), female population (0.95), educated below secondary school (0.94), 04-07 persons per room (0.93), continuation of the disease or family history (0.93), unemployment (0.91), income above PKR 15000 (0.90), patients cured in families (0.89), history of TB in their families (0.89), Punjabi speaking (0.89), patients eating meat once in a week (0.88), patient living in separate rooms $(0.86)$, patients residing in unplanned areas $(0.85)$, garbage near patients residence (0.85), Urdu speaking (0.84), patients lacking awareness regarding TB (0.84), patients sharing accommodation (0.83), patients having awareness regarding precautionary measures $(0.83)$, patients who availed treatment from the local area $(0.81)$, non-ownership households $(0.80)$, Seraiki speaking (0.78), Sindhi-speaking (0.77), income below PKR 8000 ( US\$ 80 ) (0.75), patients of other languages $(0.74)$, patients with pulmonary TB (0.74), patients who are residents of planned localities (0.74), patients living in combined family systems (0.73), patients living in katcha houses $(0.71)$, resurgence of TB 
Table 3. Rotated Component Matrix

\begin{tabular}{|c|c|c|c|c|c|c|}
\hline No & Factor I & & Factor II & & Factor III & \\
\hline 1 & Unmarried-TR & 0.98 & Cig-smoker-TMR & 0.92 & Food-2/d & 0.79 \\
\hline 2 & EPTB-TR & 0.96 & Married-TR & 0.90 & Diag-6-month-TR & 0.68 \\
\hline 3 & SSC \&Abov-TER & 0.96 & Male-TR & 0.85 & more-6-m & 0.65 \\
\hline 4 & 8-11-PPR-TR & 0.95 & Illit-TR & 0.85 & Pashto-TR & 0.20 \\
\hline 5 & Female-TR & 0.95 & Pashto-TR & 0.82 & unemp-TMR & 0.18 \\
\hline 6 & Below_SSC-TER & 0.94 & Labr-TMR & 0.80 & Other-Langu-TR & 0.14 \\
\hline 7 & 4-7-PPिTR & 0.93 & 1-3-PPR-TR & 0.79 & Unmarried-TR & 0.13 \\
\hline 8 & FH_Continue-TFH & 0.93 & Profes-TMR & 0.78 & Profes-TMR & 0.12 \\
\hline 9 & Unémp-TMR & 0.91 & FH-Died-TFHR & 0.78 & Cig-smoker-TMR & 0.12 \\
\hline 10 & $A>15000-T R$ & 0.90 & Private-TMR & 0.74 & $A>15000-T R$ & 0.11 \\
\hline 11 & FH_Cured TFHR & 0.89 & H_Wife-TFR & 0.73 & FH_Cured-TFHR & 0.11 \\
\hline 12 & Fam̄ily History TB & 0.89 & Résurgence-TR & 0.72 & Sep-Res-TR & 0.11 \\
\hline 13 & Punjabi-TR & 0.89 & PTB-TR & 0.67 & Below_SSC-TER & 0.10 \\
\hline 14 & Meat-1-/week-TR & 0.88 & Combi-Res-TR & 0.67 & BCG-N̄TR & 0.09 \\
\hline 15 & Sep-Res-TR & 0.86 & Katcha-TR & 0.65 & Family HistoryTB & 0.09 \\
\hline 16 & UnPlan-TR & 0.85 & $B<15000-T R$ & 0.65 & UnPlan-TR & 0.07 \\
\hline 17 & Garbage-TR & 0.85 & Other-Langu-TR & 0.64 & Male-TR & 0.06 \\
\hline 18 & Urdu-TR & 0.84 & Plan-TR & 0.63 & 8-11-PPR-TR & 0.06 \\
\hline 19 & Aware-No-TR & 0.84 & Seraiki-TR & 0.60 & 4-7-PPR-TR & 0.05 \\
\hline 20 & Pat-Resi-combined-TR & 0.83 & Non-ownership-TR & 0.60 & SSC \&Abov-TER & 0.05 \\
\hline 21 & precau-N-TR & 0.83 & BCG-N-TR & 0.59 & Aware-No-TR & 0.05 \\
\hline 22 & Local Treat-TR & 0.81 & Local Treat-TR & 0.59 & PTB-TR & 0.04 \\
\hline 23 & Non-ownership-TR & 0.80 & Pat-Resi-combined-TR & 0.55 & FH_Continue-TFH & 0.04 \\
\hline 24 & Seraiki-TR & 0.78 & Aware-No-TR & 0.54 & Garbage-TR & 0.04 \\
\hline 25 & Sindhi-TR & 0.77 & Sindhi-TR & 0.54 & Resurgence-TR & 0.02 \\
\hline 26 & $\mathrm{~B}<15000-\mathrm{TR}$ & 0.75 & precau-N-TR & 0.53 & Urdu-TR & 0.02 \\
\hline 27 & Other-Langu-TR & 0.74 & Urdu-TR & 0.52 & Local Treat-TR & 0.01 \\
\hline 28 & PTB-TR & 0.74 & Garbage-TR & 0.52 & Meat-1-/week-TR & 0.01 \\
\hline 29 & Plan-TR & 0.74 & Diag-6-month-TR & 0.51 & FH-Died-TFHR & -0.02 \\
\hline 30 & Combi-Res-TR & 0.73 & Sep-Res-TR & 0.48 & $B<15000-T R$ & -0.03 \\
\hline 31 & Katcha-TR & 0.71 & Meat-1-/week-TR & 0.46 & Pat-Resi-combined-TR & -0.03 \\
\hline 32 & Resurgence-TR & 0.69 & Govt S-TMR & 0.46 & 1-3-PPR-TR & -0.04 \\
\hline 33 & H_Wife-TFRF & 0.68 & UnPlan-TR & 0.45 & Non-ownership-TR & -0.04 \\
\hline 34 & H-Died-TFH & 0.62 & Family_HistoryTB & 0.44 & H_Wife-TFR & -0.06 \\
\hline 35 & R1-3-PPR-TR & 0.61 & FH_Cured-TFHR & 0.44 & Female-TR & -0.06 \\
\hline 36 & Pashto-TR & 0.53 & FH_Continue-TFH & 0.35 & Plan-TR & -0.09 \\
\hline 37 & Male-TR & 0.51 & 4-7-PPR-TR & 0.35 & Combi-Res-TR & -0.10 \\
\hline 38 & Profes-TM & 0.50 & Punjabi-TR & 0.33 & Labr-TMR & -0.11 \\
\hline 39 & RIllit-TR & 0.45 & SSC \&Abov-TER & 0.29 & Punjabi-TR & -0.12 \\
\hline 40 & Private-TMR & 0.42 & Female-TR & 0.28 & Sindhi-TR & -0.12 \\
\hline 41 & Labr-TMR & 0.39 & Below_SSC-TER & 0.24 & precau-N-TR & -0.13 \\
\hline 42 & more-6-m & 0.37 & EPTB-TR & 0.22 & Seraiki-TR & -0.14 \\
\hline 43 & Cig-smoker-TMR & 0.17 & $A>15000-T R$ & 0.17 & EPTB-TR & -0.17 \\
\hline 44 & BCG-N-TR & 0.12 & Unmarried-TR & 0.10 & Private-TMR & -0.20 \\
\hline 45 & Diag-6-month-TR & 0.09 & 8-11-PPR-TR & 0.03 & Illit-TR & -0.22 \\
\hline 46 & Diag-3-month-TR & 0.00 & Food-2/d & -0.05 & Katcha-TR & -0.23 \\
\hline 47 & Married-TR & -0.29 & Diag-3-month-TR & -0.06 & Married-TR & -0.23 \\
\hline 48 & Govt S-TMR & -0.34 & Unemp-TMR & -0.20 & Govt S-TMR & -0.50 \\
\hline 49 & Food-2/d & -0.53 & More-6-m & -0.35 & Diag-3-month-TR & -0.98 \\
\hline
\end{tabular}

Extraction Method: Principal Component Analysis.

Rotation Method: Varimax with Kaiser Normalization.a Rotation converged in 6 iterations.

among patients (0.69), housewives (0.68), patients whose family member died due to TB (0.62), patients residing in room density 01-03 persons per room (0.61), Pashto-speaking (0.53), male population (0.51) and professional employees $(0.50)$ have emerged as being responsible for spread of TB.

On the basis of correlation among variables regarding the spread of TB, Factor I has highlighted the major causes. The unmarried population has shown lowest incidence comparatively to married (37\% to total patients) due to their lower burden of responsibility, awareness of TB and independent movement around their living areas thus aiding intake of fresh air. Incidence among married (63\%) depicts socioeconomic constraints in the family where parents go hungry and share 
their food with their offspring. The need for marriage for both males and females is recognized as an essential requisite for family making. High incidence of the disease may be attributed to females' culturally rigorous and backward thinking of the resident ethnic groups (Miandad et al., 2015) because they do not allow their females to spend their time in the open environment. The pattern of employment structure among TB patients has also provided evidence for cause of the disease because $38 \%$ of disease incidence among housewives and 14\%, 12\%, 11\%, 7\%, $5 \%$, $20 \%$ and $11 \%$ respectively among labourers, self-employed, students, textile labourers, the jobless, drivers and other job categories respectively, in addition to $37 \%$ incidence stamped over unmarried patients because they live under poor socioecological conditions.

Based on all positive loadings Figure 2 portrays a high degree of explanation for Factor I in which a complex manifestation points towards earnings and sources of living in a weak city administration which are causes responsible for strengthening of mycobacterium. All the supporting variables pertain both to social, ecological and demographic parameters of urban living as being responsible for the incidence of the disease strongly supported by the disinterested city administrative authorities which does not ensure the implementation of related betterment laws, hence delegation of low standard of living under extremely congested urbanized conditions in the study area. Factor I also supports escalation in TB incidence in the study area due to environmental degradation because the depressing quality of life does not help in the organization of people's lives in an organized and civilized manner.

\section{Factor II-Socioeconomic and ecological}

The second factor explains $32.35 \%$ (Table 2) of the total variance of a geodemographic parameter of TB patients. The rotated factor matrix shows that significant highest positive loading (Table 3) have been recorded for smokers to total respondents $(0.92)$ followed by married to total respondents $(0.90)$, male to total respondents (0.85), Pashto-speaking to total respondents and laborer patients to total respondents $(0.80)$. Other supporting positive loadings have been recorded for patients residing in a condition of $01-03$ persons per room (0.61), professional employees (0.78), patient's relative died due to TB (0.78), small private businessmen (0.74), housewife (0.73), resurgence patients $(0.72)$, РТВ (0.67), patients living in combined family system (0.67), patients who lived in katcha houses (0.65), monthly income below PKR 8000 (0.65), other languages (0.64), residents of planned areas (0.63), Seraiki speaking (0.60), non-ownership household (0.60), patients who have not been vaccinated by BCG to total respondents (0.59), patients who received treatment from local areas (0.59), patients who lived in combined family systems $(0.55)$, awareness regarding TB (0.54), Sindhi-speaking (0.54), patients who had awareness regarding precautionary measures (0.53), Urdu speaking (0.52), garbage near patient's residence (0.52) and TB diagnosis before 06 months (0.51). All these variables, viewed in a general perspective, justify the entitlement of this factor as Socioeconomic cum Ecological. 


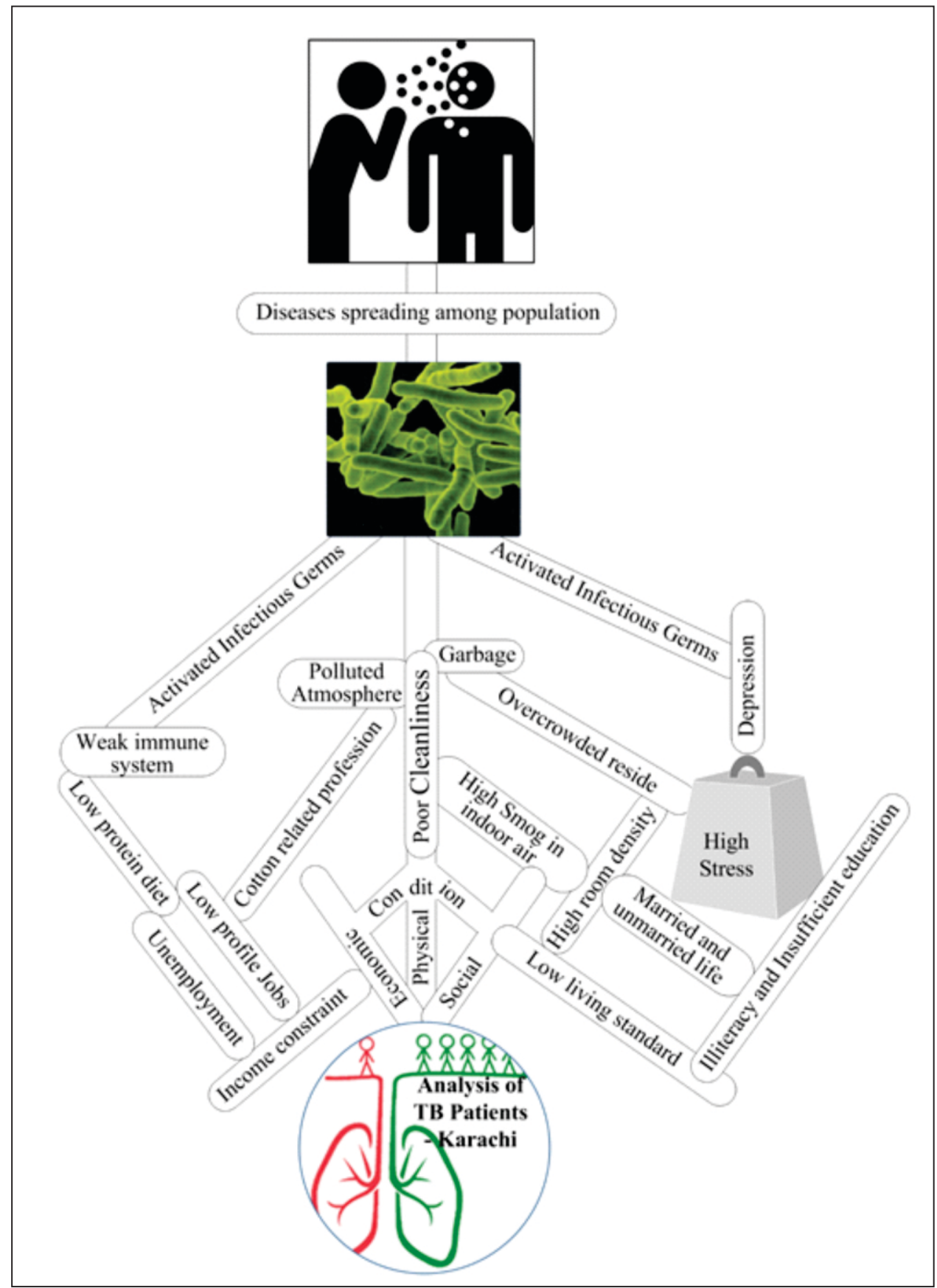

Figure 2. Major Factors responsible for spread of TB in the study area

Karachi is Pakistan's busiest port Major industries and businesses are located there. It has approximately 3600 industrial units in the formal sector. The major industries are pharmaceuticals, textile, paper, leather, marble, ceramics, rubber, stationery, glass, plastic, iron, electronics, agricultural, foods and dairy products 
(GoP, 2006). According to KDA-MPD/AERC report, (1989) $75 \%$ of the labourers are employed in the informal sector. Karachi Development Plan (KDA, 2000) focuses mainly on the textile, carpet, garment, leather and light engineering sectors in low-income settlements and in recent years, a link between formal and informal sectors has been established with the formal sector sub-contracting work to informal establishments (Hassan and Mohib, 2003).

According to KDA (2000), most of the paper industries, solid waste sorting, recycling, garment, leather tanning and manufacturing, light engineering and carpet industries, all function from within or near katchiabadies and slums. In the case of the leather and garment sectors, the formal industries contract piecemeal manufacturing of their items to skilled workers within katchiabadies through middlemen. Economic growth though directly responsible for expanding productive employment in itself cannot reduce poverty. Only productive and remunerative employment can help to reduce or eliminate poverty and deprivation.

Various studies have revealed that low-wage workers survive under extreme conditions in the study area. With an increase in poverty level, a concurrent increase in unemployment and access to basic services like health, housing and education continue to increase and poor households increasingly face distress, which is intensified by additional factors. Malnutrition, especially among children from low-income families, increases their susceptibility to infectious diseases. The risk of exposure to diseases gets magnified due to unhygienic environmental conditions in the provision of food (Hussain et al., 2003). Susceptibility to infection is increased by inability and inaccessibility of their children to BCG vaccination. In addition, provision of protective facilities like safety belts, protective eye wears, hand gloves, shoes, helmets, and masks for workers at their workplaces is far from satisfactory (Kumar, 2012).

More than 02 million workers were employed in the construction industry which is the backbone of all developmental activities. Attention should be directed towards health, safety and occupational hazards in this industry. In order to ensure health and safety of its workers, the government must enact relevant legislation for the provision of benefits like Workmen's Compensation, Social Security, Old-age Pension, etc. available to workers in other formal sectors (GoP, 2010). However, it is a major challenge to extend such type of labor protection to the workers in the large and diverse informal economy, which engages millions of people from the country's large geographic area. Numerous workers in the informal economy, engaged in low-paid, low-productivity jobs under harsh, unhealthy and hazardous conditions are not covered by labor laws (Kousar, 2010).

Various studies have identified that smoking plays a significant role in increasing the risk to TB disease (Wang et al., 2007). The very high positive loading for smokers to total respondents (0.92) has emerged as a significant variable with respect to males for $\mathrm{TB}$ growth in the study area because $81.58 \%$ male respondents out of total smokers, while $63.25 \%$ out of total male respondents and $38.06 \%$ out of total respondents recorded TB affected patients compared to females. Most of the patients fell in the age group 21-30 years followed by 51-60 and above age group. Although, a high percentage of females above 50 years old reported smoking of cigarettes due to some routine diseases such as constipation, etc. among lowincome groups. Otherwise usually smoking is strongly prohibited for females. 
Unfortunately, however, it has been observed that smoking in recent years is increasing among younger age groups of females as a fashion in emulation of TV dramas, where elite class display smoking as a fashion. This can create an alarming health situation for low-income communities as the negative impact of smoking among elites is compensated by balanced diets, which the low-income groups cannot afford, thus giving an open invitation to infections and diseases especially TB. All the social, economic, ecological and demographic factors go on in a vicious circle initiating and perpetrating TB.

Factor II is composed of 09 social, 06 economic and 08 ecological variables; thus it can be entitled socioeconomic cum ecological factor as an undercurrent. The first 06 variables are loading highest on the factor, emerged as prominent and different from that of Factor I, in addition to the variable on cigarette smokers, married and males which have emerged with high loadings. An undercurrent of the social aspect is the significance of the variable related to males, highlighting the fact that males have emerged as significant contributors to the spread of TB disease, along with gender bias as revealed in other relevant literature (Neyrollers and QuintanaMurci, 2009).

\section{Factor III - Diet and diagnosis}

The third factor explains $6.68 \%$ (Table 2) of the total variance of variables on data pertaining to TB patients. The rotated factor matrix shows that significant highest positive loading (Table 3) has been recorded for food twice a day to total respondents $(0.79)$, followed by diagnosis 06 months to total respondents $(0.68)$ and diagnosis more than 06 months to total respondents $(0.65)$. These 03 variables, viewed in a general perspective justify the entitlement of this factor as Diet and Diagnosis. Schaible and Kaufmann (2004) stated that the causes of a tendency to consumption revealed relationships among nutrition, diet and the causes of infectious disease and had recommended a balanced diet for those displaying the earliest stages of the disease.

Population increases characterized by widespread poverty, food insecurity and limited access to a healthy diet are most likely to suffer from HIV and TB epidemics. All three factors are interlinked in a vicious cycle (World Food Program). Underdeveloped regions or countries of the world suffer from malnutrition and tuberculosis where problems of considerable magnitude exist. From the narrow clinical point of view and from the broader perspective of prevention and therapeutics management of individual cases, with regard to control of tuberculosis in developing countries the prevalence of widespread malnutrition among the population poses serious problems.

Because of a whole complex of coincidental environmental factors, direct evidence of the effect of nutrition on tuberculosis is difficult to decipher. Mortality and morbidity from tuberculosis in a population facing food shortage points towards the view that malnutrition has an enormous weight, in spite of limitations regarding their contribution towards the view of exacerbation of TB. The problem of malnutrition and tuberculosis in underdeveloped countries is further aggravated by the high prevalence of HIV infection, as it is a significant factor in adversely affecting the nutritional status of patients (Gupta et al., 2009; Rao and Gopalan, 1996). 
Karachi is the financial hub of Pakistan. People of different classes and creeds reside in various areas of the megapolis commensurate with their financial capabilities and social loyalties. High-class families reside in 1000 sq. meter bungalows, while those belonging to the lower financial class live cramped up in congested dwellings; slums, katchiabadies or manage to survive in the open air. This difference between living standards was found during the surveys as well. Lowincome population being unable to afford utility expenditures, house rent, maintenance, school fees of children, quality food eke out a living under such conditions. All these problems are magnified by malnutrition which goes on in a vicious cycle. Diet and TB are linked to each other. A balanced diet helps maintain the body immune system hence all types of resistance inclusive to that of mycobacterium becomes strong. Poverty prevents people from purchase and consumption of good quality nutritious food, thus further reducing their immunity. Infection with HIV further exacerbates the chances of contracting infectious diseases like tuberculosis. Patients' food intake per day as this variable reveals the highest loading in Factor III. Highest values for patients of both sexes (males $38.75 \%$ and females $40 \%$ ) in the age group $60+$ have emerged as being TB patients.

The proportion of TB patient respondents in different age groups in terms of food intake reveals that the percentage of female respondents was greater than that of males. i.e. 52.5 compared to $47.5 \%$. The percentage of female as well as male respondents in the age group $60+$ was highest (i.e. $40 \%)$ and $(38.75 \%)$ respectively. The lowest intake of food twice a day has been recorded both among males and females was in the age group 41-50, $07 \%$ for males and lowest for females i.e. $8.5 \%$. As revealed by field observation, elderly people of both sexes have been found to be facing the problem of low calorie/food intake which is an alarming health revelation. Food intake is better among the younger age groups compared to that of the older. According to the WHO and Stop TB partnership, undernourishment and weak resistance power were recognized as threats for TB. Sufficient food can help reduce starvation while healthy nutrition can help avoid infection, reinforce the immune system and prevent unintentional weight loss caused by TB.

Late diagnosis is a major risk factor in underdeveloped countries. Among more than two-thirds of the patients, the private sector was the first choice for seeking treatment. Delay in availing treatment facilities was due to a number of factors e.g. economic, socio-demographic, pursuing non-specialized personnel for care, visiting several health care providers before final diagnosis, wastage of time in reaching healthcare facilities, etc. (Dye et al., 1999). A vicious cycle of repeated visits to same level health care centers was the core problem leading to delay in access to specialized TB services hence delayed diagnosis, resulting in prolonged nonspecific antibiotic treatment. Specialized TB service centers provide specific TB treatments (Storla et al., 2008).

\section{Conclusion}

The occurrence of $\mathrm{TB}$ has shown an increasing trend in the study area, and distribution of males and females with a marginal difference were found. The TB patients' quality of life is strongly undermined due to low income and congested 
residence (among respondents) in the study area. The geodemographic analysis with an added insight into administrative authorities and the ethnic element supports a multi-factorial theorization of tuberculosis and provides a relevant context concerning disease transmission with the local environmental, cultural and politico-economic processes.

The study has a number of implications for researchers, policy makers and healthcare providers at both public and private sectors. The present study has identified that TB patients mainly comprise the labor class with low literacy, low incomes and hence extremely poor household hygienic conditions, which go on in a vicious cycle perpetrating poverty and disease. In the perspective of TB control, the government should build better housing schemes under the domain of quality living and also make efforts to control housing density and construction on encroached land. In addition, the administration should ensure the promotion of the significance of quality food, as well as develop open green spaces in overcrowded residential areas. It is also necessary for communities to improve interaction among other groups which reside in close proximity to their settlements. Such ameliorative activities will act as an impetus in changing and improving lifestyles and cultures hence trigger improvement of health.

\section{Acknowledgements}

Authors are thankful to Dr. Iqbal Hussain and Dr. Hazoora Shaikh, Deputy Directors, TB Control Program Karachi and Dr. Nisar Ahmed Rao Pulmonologist, Ojha Institute, Karachi and Dr. Syed Ghulam Abbas Naqvi, Zonal TB Coordinator PTP, Karachi for support during the surveys.

\section{References}

Abdi, H, Lynne, J, Williams, L \& Valentin, D 2013, 'Multiple factor analysis: principal component analysis for multitableandmultiblock data sets', Wiley Periodicals, vol. 2, no. 4, pp. 1-31.

Aggarwal, AN 2010, 'Health-related quality of life: A neglected aspect of pulmonary tuberculosis', Lung India, vol. 27, no. 1, pp. 1-3.

Borraccino, A, Migliore, E, Piccioni, P, Baussano, L, Carosso, A \& Bugiani, M 2014, 'Yield of tuberculosis contact investigation in a low-incidence country', Journal of Infection, vol. 68, no. 5, pp. 448-454.

Burke, F, Azam, M, Huda, SN, Hamza, S \& Haque, Q 2008, 'Quality of Life and Cause \& Effect Relationship with Resources and Facilities - Case Study of Selected Towns in Karachi Pakistan, Journal of Social Sciences, vol. 5, no. 3, pp. 268-279.

Cattell, H \& Meade, A 2008, 'The sixteen personality factor questionnaire' in The Sage Handbook of Personality Theory and Assessment, pp. 135 - 159, Thousand Oaks, CA: Sage Publications.

Cegielski, P \& McMurray, DN 2004, 'The relationship between malnutrition and tuberculosis: evidence from studies in humans and experimental animals', The International Journal of Tuberculosis and Lung Disease, vol. 8, no.3, pp. 286-298.

Diwan, VK \& Thomson, A 1999, 'Sex, gender and tuberculosis', Lancet, vol. 353, no. 9157, pp. 1000-1001.

Dye, C, Scheele, S, Dolin, P, Pathania, V \& Raviglione, MC 1999, 'Consensus statement. Global burden of tuberculosis: estimated incidence, prevalence, and mortality by country', 
WHO Global Surveillance and Monitoring Project, JAMA, vol. 282, no. 7, pp. 677-686.

Ezzati, M \& Lopez, AD 2004, 'Comparative Quantification of Health Risks: Smoking and oral tobacco use', WHO; viewed 15 December 2011, http://tinyurl.com/j5oyvot.

GoP 2010, Pakistan labourPolicy. Government of Pakistan, Islamabad, Pakistan.

GoP 2006, Census of Manufacturing Industries - 205-06, Govt. of Pakistan. Islamabad.

Gupta, KB, Gupta, R, Atreja, A, Verma, M \& Vishvkarma, S 2009, 'Tuberculosis and nutrition', Lung India, vol. 9, no. 1, pp. 16-26.

Harling, G \& Castro, MC 2014, 'A spatial analysis of social and economic determinants of tuberculosis in Brazil', Health छ Place, vol. 25, pp. 56-67.

Hasan, A \& Mohib, M 2003, Urban Slums Reports: The case of Karachi, Pakistan, Understanding Slums: Case Studies for the Global Report on Human Settlements, viewed 10 December 2014, http://tinyurl.com/knn6xvv.

Hayward, AC \& Watson, JM 1995, 'Tuberculosis in England and Wales 1982-1993: Notifications exceed predictions', Communicable Disease Report, vol. 5, no. 3, pp. 29-33.

Hossain, S, Quaiyum, MA, Zaman, K, Banu, S, Husain, MA, Islam, MA, Cooreman, E, Borgdorff, M, Lonnroth, KM, Salim, A, H \& Leth, F 2012, 'Socio-Economic Position in TB Prevalence and Access to Services: Results from a Population Prevalence Survey and a Facility-Based Survey in Bangladesh', PLOS One, vol. 7, no. 9, pp. 1-8.

Huda, SN, Burke, F, Anwar, E, Ahmed, I, Miandad, M \& Azam, M 2013, 'Spatial analysis of sulfur dioxide (SO2) concentration in Karachi, Megapolis, Pakistan', Lasbela University Journal of Science and Technology, vol. 2, no. pp. 1-18.

Huda, SN, Burke, F, Azam, M \& Gadiwala, S 2013, 'Social and economic inequality in Sindh A factorial analysis approach', International Journal of Sociology and Anthropology, vol. 5, no.6, pp. 205-218.

Hussain, A, Kemal, AR, Hamid, AI, Ali, I, Mumtaz, K \& Qutub, A 2003, Pakistan National Human Development Report, poverty, growth and governance, Pakistan, United Nations Development Program, Oxford University Press.

Jenkins, HE, Gegia, M, Furin, J, Kalandadze, I, Nanava, U, Chakhaia, T \& Cohen, T 2014, 'Geographical heterogeneity of multidrug-resistant tuberculosis in Georgia, January 2009 to June 2011', Euro Surveill, vol. 19, no. 11, pp. 1-10.

Kaulagekar, A \& Radka, A 2006, 'Social status makes a difference: tuberculosis scenario during national family health survey', Indian Journal of Tuberculosis, vol. 54, pp. 17-23.

KDA 2000, 'Karachi Development Plan', Karachi Development Authority, Karachi, Pakistan.

KDA-MPD/AERC 1989, 'Socio-economic Profile of Planned Areas and Katchiabadis', Karachi Development Authority, Karachi, Pakistan.

Khan, JA, Irfan, M, Zaki, A, Beg, M, Hussain, SF \& Rizvi, N 2006, 'Knowledge, attitude and misconceptions regarding tuberculosis in Pakistani patients', Journal of the Pakistan Medical Association, vol. 56, no. 5, pp. 211-214.

Kousar, T 2010, Women's' Contribution to the family budget: Informal labor market in Pakistan - A case study of Bahawalpur District, Ph.D. thesis, Bahauddin Zakariya University, Multan, viewed 31 May 2014, http://tinyurl.com/jm2fxgr.

Kruuner, A, Hoffner, SE, Sillastu, H, Danilovits, MD, Levina, KL, Svenson, S, B, Ghebremichael, S, Koivula, T \& Kallenius, G 2001, 'Spread of Drug-Resistant Pulmonary Tuberculosis in Estonia', Journal of Clinical Microbiology, vol. 39, no. 9, pp. 3339-3345.

Kumar, MD 2012, 'Inimitable Issues of Construction Workers: Case Study', British Journal of Economics, Finance and Management, vol. 7, no. 2, pp. 42-53.

Landres, PB 1992, 'Ecological Indicators: Panacea or Liability?' in DH, McKenzie, DE, Hyatt \& VJ McDonald (eds), Ecological Indicators, Elsevier Applied Science, New York, pp. 12951318.

Lawn, SD 2000, 'Tuberculosis in Ghana: Social stigma and compliance with treatment', The International Journal of Tuberculosis and Lung Disease, vol. 4, no. 12, pp. 1190-1200.

Lonnroth, K, Jaramillo, E, Williams, BG, Dye, C \& Raviglione, M 2009, 'Drivers of tuberculosis epidemics: the role of risk factors and social determinants', Social Science $\mathcal{E}^{\circ}$ 
Medicine, vol. 68, no. 12, pp. 2240-2246.

McMurray, DN \& Cegielski, P 2007, 'The influence of nutrition on the risk and outcomes of tuberculosis' in HIV/AIDS, TB and Nutrition Scientific Inquiry into the Nutritional Influence on Human Immunity with Special Reference to HIV Infection and Active TB in South Africa, Academy of Sciences of South Africa, Pretoria.

Mangtani, P, Jolley, DJ, Watson, JM \& Rodrigues, LC 1995, 'Socioeconomic deprivation and notification rates for tuberculosis in London during 1982-91', BMJ, vol.310, pp. 963-966.

Miandad, M, Burke, F, Huda, SN, Ghazi, S \& Azam, M 2015, 'Lingual Distribution of Tuberculosis Patients in Karachi - A Demographic Analysis', Journal of Basic Es Applied Sciences, vol. 11, pp. 74-80.

Miandad, M, Burke, F, Huda, SN \& Azam, M 2014,'Tuberculosis incidence in Karachi: A spatiotemporal analysis', Geografia - Malaysian Journal of Society and Space, vol. 10, no. 5, pp. 01-08.

Middelkoop, K, Bekker, L, Morrow, C, Zwane, E \& Wood, R 2009,'Childhood tuberculosis infection and disease: A spatial and temporal transmission analysis in a South African township', South African Medical Journal, vol. 99, no. 10, pp. 738-743.

Myers, WP, Westenhouse, JLH, Flood, J \& Riley, LW 2006, 'An Ecological Study of Tuberculosis, Transmission in California', American Journal of Public Health, vol, 96, no. 4, pp. 685-690.

Nair, DM, George, A \& Chacko, KT 1997, 'Tuberculosis in Bombay: new insights from poor urban patients', Health Pol Plann, vol. 12, no. 1, pp. 77-85.

Neyrolles, O \& Quintana-Murci, L 2009, 'Sexual Inequality in Tuberculosis', PLOS Medicine, vol. 6 , no. 12.

NTPP 2012, National Tuberculosis Control Programme, Pakistan, Annual Report, Ministry of Health and Coordination, Government of Pakistan. Islamabad.

Nunes, C 2007, 'Tuberculosis incidence in Portugal: spatiotemporal clustering', International Journal of Health Geographics, vol. 6, pp. 1-30.

Oxlade, O \& Murray, M 2012, 'Tuberculosis and Poverty: Why Are the Poor at Greater Risk in India?', PLOS One, vol. 7, np. 11, pp. 1-8.

Ploubidis, GB, Palmer, MJ, Blackmore, C, Lim, TA, Manissero, D, Sandgren, A \& Semenza, JC 2012, 'Social determinants of tuberculosis in Europe: a prospective ecological study', European Respiratory Journal, vol. 40, no. 4, pp. 925-930.

Qazi, MA, Sharif, N, Warraich, MM, Imran, A, Haque, IU, Attique, MUH, Gardezi, M, A \& Chaudhary, GM, 2009, 'Radiological Pattern of Pulmonary Tuberculosis in Diabetes Mellitus', $A N N A L S$, vol. 15, no. 2, pp. 71-74.

Rao, KN \& Gopalan, C 1966, 'The role of nutritional factors in tuberculosis', Indian Journal of Tuberculosis, vol. 13, no 3, pp. 102-106.

Roza, DL, Caccia-Bava, M \& Martinez, EZ 2012, 'Spatio-temporal patterns of tuberculosis incidence in RibeirãoPreto, State of São Paulo, Southeast Brazil, and their relationship with social vulnerability: a Bayesian analysis', Revista da Sociedade Brasileira de Medicina Tropical, vol. 45, no. 5, pp. 607-615.

Schaible, UE \& Kaufmann, SHE 2004, 'Iron and microbial infection', Nature Reviews, vol. 2, no. 12, pp. 946-954.

Shafqaat, M \& Jamil, S 2012,'The distribution of tuberculosis patients and associated Socioeconomic risk factors for transmission of Tuberculosis disease in Faisalabad city', Asian Journal of Natural \& Applied Sciences, vol. 1, no. 1, pp. 90-95.

Siddiqui, MS, Fakih, HAM, Burney, WA, Iftikhar, R \& Khan, N 2011, 'Environmental and Host-Related Factors Predisposing to Tuberculosis in Karachi: A Cross-Sectional Study', Journal of Pakistan Medical Students, vol. 1, no. 1, pp. 13-18.

Souza, WV, Ximenes, R, Albuquerque, MFM, Lapa, TM, Portugal, JL, Lima, ML \& Martelli, CMT 2000, 'The use of socioeconomic factors in mapping tuberculosis risk areas in a city of northeastern Brazil', Revista Panamericana de Saul Publica, vol. 8, no. 6, pp. 403-410.

Storla, DG, Yimer, S \& Bjune, GA 2008, 'A systematic review of delay in the diagnosis and 
treatment of Tuberculosis', BMC Public Health, vol. 8, pp. 7-15.

UN 2005, The Millennium Development Goals Report 2005, New York.

Wang, JY, Hsueh, PR, Jan, IS, Lee, LN, Liaw, YS, Yang, PC \& Luh, KT 2007, 'The effect of smoking on tuberculosis: different patterns and poorer outcomes', The International Journal of Tuberculosis and Lung Disease, vol. 11, no. 2, pp. 143-149.

Wang, T, Xue, F, Chen, Y, Ma, Y \& Liu, Y 2012, 'The spatial epidemiology of tuberculosis in Linyi City, China, 2005-2010', BMC Public Health, vol. 12, pp. 879-885.

Weinbach, WR \& Grinnell, MRJR 2001, Statistics for Social Workers, $5^{\text {th }}$ edn, Allyn and Bacon, USA.

WHO 2013, World Health Organization, Annual Report, viewed 10 May 2014, www.who.int/whr/en/.

Wirth, T, Hildebrand, F, Allix-Beguec, C, Wolbeling, F, Kubica, T, Kremer, K, Soolingen, D, Rusch-Gerdes, S, Locht, C, Brisse, S, Axel Meyer, A, Supply, P \& Niemann, S, 2008, 'Origin, Spread and Demography of the Mycobacterium tuberculosis Complex', PLOS Pathogens, vol. 4, no. 9, pp. 1-10.

Yazdani, J, Charati \& Kazemnegad, A 2010, 'Spatial Distribution of Tuberculosis in Mazandaran Province-Iran: Spatiotemporal Modeling', Tanaffos, vol. 9, no. 3, pp. 15-21. 